Article

\title{
Composite Aerogels of Carbon Nanocellulose Fibers and Mixed-Valent Manganese Oxides as Renewable Supercapacitor Electrodes
}

\author{
Xiaoyu Guo, Qi Zhang, Qing Li *, Haipeng Yu * and Yixing Liu * \\ Key Laboratory of Bio-Based Material Science and Technology, Ministry of Education, Northeast Forestry \\ University, Harbin 150040, China; guoxiaoyu666@163.com (X.G.); qzhang_2013@163.com (Q.Z.) \\ * Correspondence: liqing007007@126.com (Q.L.); yuhaipeng20000@nefu.edu.cn (H.Y.); \\ yx1200488@sina.com (Y.L.); Tel.: +86-451-8219-1748 (H.Y.)
}

Received: 2 December 2018; Accepted: 3 January 2019; Published: 13 January 2019

\begin{abstract}
Bio-waste derived nanocelluloses show excellent mechanical flexibility and self-aggregated capability, which enable them to be good supporting substrates for the synthesis of electroactive materials. Herein, we present a facile route for fabricating composite aerogels consisting of carbonized nanocellulose fibers (CNF) and mixed-valent manganese oxide $\left(\mathrm{MnO}_{x}\right)$, toward supercapacitor applications. Mixed solutions of nanocellulose and manganese acetate with different ratios were prepared and freeze-dried into hybrid aerogels. The hybrid aerogels were then transformed into $\mathrm{CNF} / \mathrm{MnO}_{x}$ composites by a calcination process. The CNF membranes served as porous carbon nano-reservoirs for $\mathrm{MnO}_{x}$ and electrolyte. The $\mathrm{CNF} / \mathrm{MnO}_{x}$ composites also kept a 3D porous aerogel structure with hierarchical pores, which enabled stable transport of both electrolyte ions and electrons to the electrode surface, leading to low a charge-transfer impedance and good electrochemical kinetics. The $\mathrm{CNF} / \mathrm{MnO}_{x}$-based symmetric supercapacitor showed a satisfied energy density and power density of $37.5 \mathrm{Wh} \mathrm{kg}^{-1}$ and $2.75 \mathrm{~kW} \mathrm{~kg}^{-1}$, respectively. All the above results demonstrate the feasibility of using sustainable nanocellulose as a nanoscale carbon substrate for the synthesis of hybrid composite electrodes toward renewable supercapacitor applications.
\end{abstract}

Keywords: nanocellulose; manganese oxide; aerogel; composite; supercapacitor electrode; electrochemistry

\section{Introduction}

Parallel to the growing need for renewable energy supply, there is an increasing demand for high-performance power sources with low-cost, lightweight, portable, and environmentally friendly features. Supercapacitors have emerged as a promising candidate for electrochemical energy storage because of their fast charge-discharge processes, providing a high energy density and a reasonable power density [1]. Both the materials and the structures are the cruxes in developing high-performance supercapacitors [2]. In terms of the materials, despite offering key performance advantages, many components are often expensive and contain fluorine, sulfur, and cyanide groups, which pose environmental hazards if discarded and disposed of using conventional landfill or incineration methods. Also, the derived supercapacitors sometimes suffer from a low energy density. Aiming at solving these problems, various categories of redox-reaction materials, including metal oxides, conductive polymers, and hybrid materials, have been employed as electrodes to dramatically improve the energy density. In regard to the structure, one key challenge is to achieve a high loading of electroactive materials per unit area with good contact of the electrodes. As the appeal of hybrid structures lies in the synergistic effects based on interfacial charge and energy transfer processes, controlling the nature of the interface and maximizing the interfacial area become critical issues. 
There is no doubt that hybrid structures of different nanomaterials would extend the diversity of micro- and macrostructures, with good integrated physical/chemical properties inherited from the constituent structures [3]. Manganese oxide $\left(\mathrm{MnO}_{x}\right.$, i.e., $\mathrm{Mn}$ atoms with multiple oxidation states and phases) is an inexpensive pseudocapacitive material exhibiting high theoretical capacitance [4-6]. However, the small surface area and low conductivity of $\mathrm{MnO}_{x}$ result in a poor charge-discharge rate for high-power applications. The combination of pseudocapacitive materials with carbon materials represents an important breakthrough for developing novel composite electrodes with improved performance [7].

Carbon materials are currently the most popular electrode materials used in supercapacitors. Among them, carbon nanotubes, graphene, and activated carbon have been investigated intensively in recent years [8-10]. However, the high cost of carbon nanomaterials and the complex preparation process (liquid phase deposition, electrodeposition, hydrothermal reaction, cyclic voltammetric anodic deposition, etc.) limit the fast development of carbon $/ \mathrm{MnO}_{x}$ electrode materials [11-17]. From both an availability and cost perspective, sustainable biochar and biochar nanomaterials are expected to be exploited to replace nonrenewable carbon materials [18-22]. Currently, activated carbons derived from biomass polymers have been identified as the most viable materials for supercapacitors [23-25]. A recent trend is the utilization of hierarchical porous graphitic carbons (HPGC), which combine the macroporous cores, mesoporous walls and micropores, as excellent support for metal oxides [26-28]. HPGC shows great potential in energy storage because of their high surface areas as well as short ion transport path $[29,30]$. However, most existing protocols rely heavily on nanocasting and soft templating, which usually use specific materials and thus make their industrial application unfeasible. Aiming at solving this problem, aerogels composed by nanocellulose have been considered as precursors of HPGC [31,32]. As a novel nanomaterial synthesized by biomass resources, nanocellulose was recognized as a sustainable building block for energy storage owning to its intrinsic structures and performance, as well as its renewable and abundant raw resources [33]. A large number of oxygen-containing functional groups on nanocellulose make them easier to decorate with electroactive materials and to modify the physicochemical properties [34-39]. Therefore, nanocellulose-based composite aerogel represents a versatile matrix to prepare lightweight hybrid materials [40-44]. Yang et al. have integrated spherical manganese dioxide nanoparticles and other kinds of active nanomaterials with the cellulose nanocrystal (a type of nanocellulose) aerogels, and lightweight, highly porous, and flexible hybrid aerogels for the development of supercapacitor materials [45]. Excellent capacitance retention at high charge-discharge rates was achieved due to the high mass ratio of active material to the total electrode mass, indicating the big potential of utilization of nanocellulose for high performance supercapacitors.

In this work, we aim to use forest waste-derived nanocellulose aerogel as the carbon nanomaterials and the nano-reservoirs for pseudocapacitive materials. Our nanocellulose exhibits high aspect ratio and can form strong entangled networks, resulting in self-standing and robust aerogels. Besides, the surface of nanocellulose contains large amounts of hydroxyl groups, which is good for the uniform integration of nanocellulose with the precursor of the active materials within the suspension. In addition, the nanocellulose composite aerogels can be effectively converted to carbon aerogels, which provides an efficient way for the integration of large amounts of electro-chemistry active materials into the carbon network to improve the ability for charge storage. The as-generated $\mathrm{CNF} / \mathrm{MnOx}$-based symmetric supercapacitor showed a satisfied energy density and power density. We hope our work can stimulate interest in the development of a "green" carbon source from biomass resources such as wood for advanced electrochemistry energy storage applications. 


\section{Experimental Section}

\subsection{Preparation of Nanocellulose Suspension}

Nanocellulose was extracted according to the method reported before [46]. Wood flour was first subjected to mild chemical pretreatment using acidified sodium chlorite and $\mathrm{KOH}$ to remove the lignin and hemicelluloses. After purification, the solution with $1 \mathrm{wt} . \%$ purified cellulose was ultrasonically disintegrated using a JY99-IIDN ultrasonicator (Scientz Biotechnology Co., Ningbo, China) at $1200 \mathrm{~W}$ for $20 \mathrm{~min}$, resulting in a $1 \mathrm{wt}$.\% nanocellulose suspension.

\subsection{Preparation of CNF/MnO ${ }_{x}$ Composite Aerogels}

Typically, $0.1 \mathrm{~g}$ polyvinyl pyrrolidone (PVP) (Blue Season Technology Development Co. Ltd., Shanghai, China) and manganese acetate $\left(\mathrm{Mn}(\mathrm{OAc})_{2}\right)$ (Komeo Chemical Reagent Development Center, Tianjin, China) $(0.02,0.06,0.10$, and $0.14 \mathrm{~g})$ were added in a $20 \mathrm{~g}$ nanocellulose suspension and mechanically stirred for $1 \mathrm{~h}$. The mixed solutions were frozen in a refrigerator at $-18{ }^{\circ} \mathrm{C}$ for $24 \mathrm{~h}$. Afterwards, they were subjected to freeze-drying using a Scientz-10N freeze dryer (Scientz Biotechnology Co., Ltd., Ningbo, China). The resultant hybrid aerogels were calcinated in a nitrogen atmosphere in an SK-G08123K tube furnace (Zhonghuan Experimental Furnace Co. Ltd., Tianjin China). The temperature rose from room temperature to $850{ }^{\circ} \mathrm{C}$; the heating rate was $3^{\circ} \mathrm{C} \mathrm{min}^{-1}$. During the calcination process, the samples were kept at $270{ }^{\circ} \mathrm{C}$ for $1 \mathrm{~h}, 450{ }^{\circ} \mathrm{C}$ for $1 \mathrm{~h}$, and $850{ }^{\circ} \mathrm{C}$ for $2 \mathrm{~h}$, after the temperature dropped to room temperature. Finally, the $\mathrm{CNF} / \mathrm{MnO}_{x}$ composite aerogels were obtained. The composite aerogels were denoted as $\mathrm{CNF} / \mathrm{MnO}_{x}-m$, where $m$ takes on the value $1,2,3$, or 4 , respectively. Determined by the thermogravimetric analysis (TGA), the mass fraction of $\mathrm{MnO}_{x}$ in the $\mathrm{CNF} / \mathrm{MnOx}-m$ were calculated as ca. $6 \%, 18 \%, 30 \%$, and $41 \%$, respectively (Figure S1).

\subsection{Preparation of Electrodes and Supercapacitors}

The electrode was prepared by loading a slurry containing $\mathrm{CNF} / \mathrm{MnO}_{x}-m$, poly(vinylidene fluoride) (PVDF) (in N-methylpyrrolidone), and acetylene black (8:1:1 wt.\%) on a nickel collector. After the mixed materials were loaded, the electrode was pressed and dried in vacuum at $80^{\circ} \mathrm{C}$ for $12 \mathrm{~h}$. In the case of a three-electrode system, an Au-coated polyethylene terephthalate substrate was used as a working electrode, a mercurous sulfate electrode as the reference electrode, and $\mathrm{Pt}$ wire as the counter electrode. $1.0 \mathrm{M} \mathrm{Na}_{2} \mathrm{SO}_{4}$ solution was used as an electrolyte. A symmetric supercapacitor was assembled using two pieces of $1.5 \times 1.5 \mathrm{~cm} \mathrm{CNF} / \mathrm{MnO}_{x}$ electrodes (the average weight of each electrode was $2.0 \mathrm{mg}$ ), with $1.0 \mathrm{M} \mathrm{LiPF}_{6}$ ethylene carbonate/diethylene carbonate/ethyl-methyl carbonate (EC/DEC/EMC) (1:1:1 v/v/v) electrolyte-soaked separator in between.

\subsection{Characterizations}

A JEM-2100 transmission electron microscope (TEM, JEOL Ltd., Tokyo, Japan) was used for the TEM imaging. Scanning electron microscopy (SEM) images were taken on a Quanta200 microscope (FEI, Hillsboro, OR, USA), at an operating voltage of $15 \mathrm{kV}$. The surface chemical composition was determined by an energy-dispersive X-ray (EDX) spectroscope connected to the SEM. Nitrogen adsorption-desorption isotherm measurements were performed using a 3H-2000PM2 Brunauer-Emmett-Teller (BET) surface area analyzer (Micromeritics, Beishide Instrument-ST Ltd., Beijing, China). The samples were degassed at $300{ }^{\circ} \mathrm{C}$ under vacuum for $5 \mathrm{~h}$ before the measurements. Specific surface area was calculated using the BET method. The total pore volume was determined at a relative pressure of 0.98 . Pore volume and pore-size distribution were calculated using a nonlocal density functional theory (NLDFT) model based on the nitrogen adsorption branches of the isotherms. X-ray photoelectron spectroscopy (XPS) was performed using a K-Alpha system (Thermo Fisher Scientific, West Sussex, UK) operated at $14.0 \mathrm{kV}$ and all binding energies were referenced to the $C 1 \mathrm{~s}$ neutral carbon peak at $284.8 \mathrm{eV}$. X-ray diffraction (XRD) patterns were obtained using a D/max 2200 
X-ray diffractometer (Rigaku, Tokyo, Japan) with Ni-filtered $\mathrm{CuK}_{\alpha}(\lambda=1.5406 \AA$ ) radiation at $40 \mathrm{kV}$ and $30 \mathrm{~mA}$. Scattered radiation was detected in the range of $2 \theta=10^{\circ}-80^{\circ}$ at a scan rate of $4^{\circ} \mathrm{min}^{-1}$.

\subsection{Electrochemical Measurements}

Electrochemical measurements including cyclic voltammetry (CV) curves, galvanostatic charge-discharge (GCD) curves, and electrochemical impedance spectroscopy (EIS) were conducted on a CHI 660D electrochemical workstation (Chenhua Instrument Co., Shanghai, China) at room temperature. The electrochemical performance of individual electrodes was investigated using a three-electrode system prior to the fabrication of the supercapacitors. CV measurements were performed at different scan rates $\left(2-100 \mathrm{mV} \mathrm{s}^{-1}\right)$, within a potential window of -0.5 to $0.5 \mathrm{~V}$. GCD measurements were performed with a constant current from $0.25-2 \mathrm{~A} \mathrm{~g}^{-1}$. EIS measurements were conducted for the working electrode in a frequency range of $100 \mathrm{kHz}$ to $0.01 \mathrm{~Hz}$ with alternating current $(\mathrm{AC})$ perturbation of $5 \mathrm{mV}$. The EIS data were analyzed using Nyquist plots, which represent the imaginary part $\left(Z^{\prime}\right)$ and the real part $\left(Z^{\prime \prime}\right)$ of impedance. The performance of the supercapacitors was measured using a two-electrode method at scan rates of $5-100 \mathrm{mV} \mathrm{s}^{-1}$ within a potential window of 0 to $3.5 \mathrm{~V}$.

The specific capacitance $\left(C, \mathrm{~F} \mathrm{~g}^{-1}\right)$ was calculated from the corresponding GCD curves at different current densities according to the equation:

$$
C=I /[(d V / d t) m]=\frac{I}{m} \frac{d t}{d V}
$$

where $I(\mathrm{~A})$ is the response current, $m$ is the average mass of the electrode, and $d t / d V$ is the inverse of the slope of the discharge curve $\left(\mathrm{V} \mathrm{s}^{-1}\right)$.

The maximum specific energy density $\left(E_{\max }\right)$ and power density $\left(P_{\max }\right)$ were calculated according to the equations below:

$$
\begin{gathered}
E_{\max }=0.5 C V_{\max }^{2} / 3.6 \\
P_{\max }=3600 E_{\max } / t
\end{gathered}
$$

\section{Results and Discussion}

The preparation procedure of the $3 \mathrm{D}$ porous $\mathrm{CNF} / \mathrm{MnO}_{x}$ composite electrodes for supercapacitors is illustrated in Figure 1. First, nanocellulose fibers were disintegrated from wood waste through biorefinery steps. The resultant nanocelluloses exhibited fibrous structures with 2-20 nm widths and lengths exceeding $1 \mu \mathrm{m}$ (Figure 2a) [47]. Because of high aspect ratios and numerous hydroxyl groups being exposed, the nanocellulose fibers are likely to intertwine together, which facilitates the formation of the gel network, particularly for mass concentrations above $0.8 \mathrm{wt} . \%$ [48]. Subsequently, the nanocellulose suspension was mixed with $\mathrm{Mn}(\mathrm{OAc})_{2}$ solutions containing different concentrations of solute, and freeze-dried into freestanding hybrid aerogels with tailored shapes and sizes. The obtained hybrid aerogels showed no significant differences in appearance compared with the nanocellulose aerogels. After calcination at $850^{\circ} \mathrm{C}$ in an argon atmosphere, the hybrid aerogels turned into $\mathrm{CNF} / \mathrm{MnO}_{x}-m$ composite aerogels, and the colors changed into black (Figure $2 \mathrm{~b}$ ). The shape of the composites was maintained but the volume shrunk by almost $40 \%$. Thus, the bulk density increased from $0.01 \mathrm{~g} \mathrm{~cm}^{-3}$ to $0.16 \mathrm{~g} \mathrm{~cm}^{-3}$. Meanwhile, the composites exhibited flexible and elastic features. 


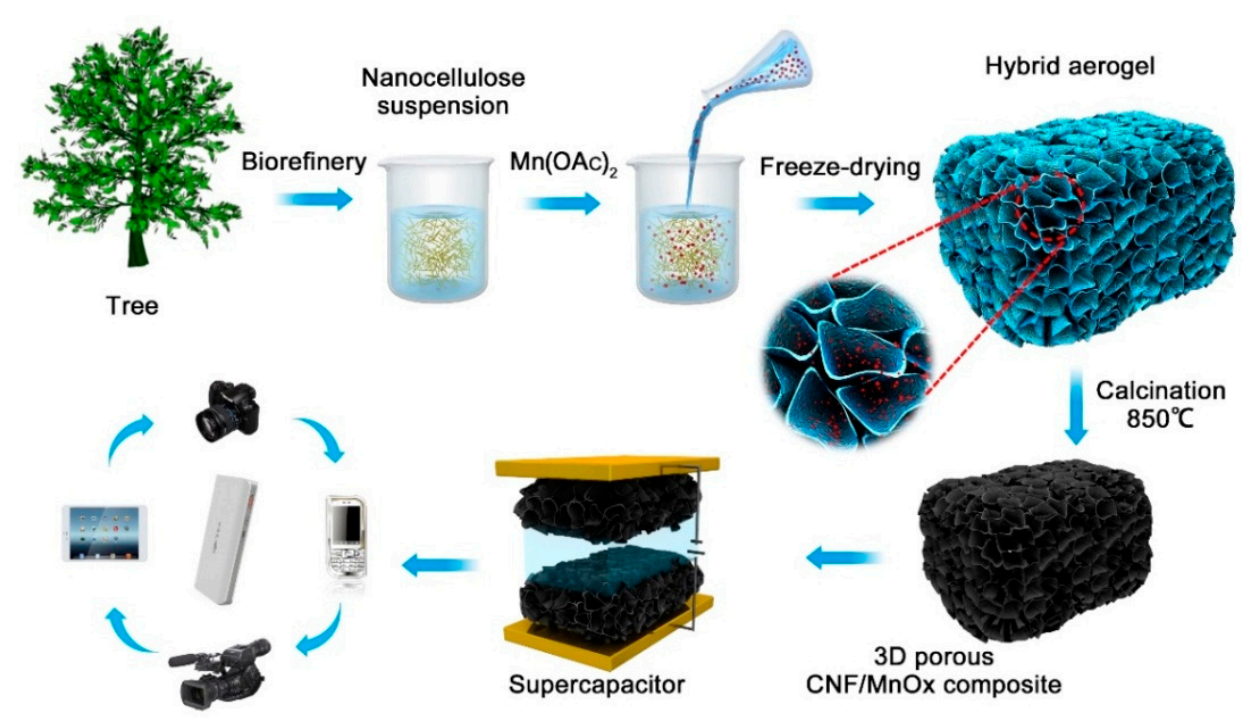

Figure 1. Schematic illustration of the preparation procedure of 3D porous carbonized nanocellulose fibers $(\mathrm{CNF}) / \mathrm{MnO}_{x}$ composite electrodes for supercapacitor applications.

SEM and high-resolution TEM were applied to investigate the microstructure of the CNF/ $\mathrm{MnO}_{x}$ composite aerogels. The SEM images of the CNF aerogel in Figure $2 \mathrm{c}, \mathrm{d}$ show the 3D porous structure made of carbon nanofiber membranes. The $\mathrm{CNF} / \mathrm{MnO}_{x}$ composite aerogels also exhibit a similar 3D network structure (Figure 2e). The SEM-EDX elemental mapping images of $\mathrm{C}, \mathrm{Mn}$, and $\mathrm{O}$ atoms evidently display the homogeneous distribution of $\mathrm{MnO}_{x}$ nanoparticles on the surfaces of the CNF membranes (Figure $2 \mathrm{f}-\mathrm{h}$ ). The high-resolution TEM image and the selected area electron diffraction (SAED) cyclic pattern in Figure $2 \mathrm{j}$ further reveal the graphite carbon structure of the CNF membranes. The $\mathrm{MnO}_{x}$ nanoparticles that attached to the CNF membranes possess typical crystalline nanodomains (Figure 2k). The CNF aerogel has a high BET surface area $\left(S_{\mathrm{BET}}\right)$ value of $554.8 \mathrm{~m}^{2} \mathrm{~g}^{-1}$, whereas that of $\mathrm{CNF} / \mathrm{MnO}_{x}-4$ drops to $219.3 \mathrm{~m}^{2} \mathrm{~g}^{-1}$. The pore sizes of $\mathrm{CNF} / \mathrm{MnO}_{x}-4$ were calculated $1.99-305.3 \mathrm{~nm}$ from the pore-size distribution curves. The mesopore $(2.0-58.0 \mathrm{~nm})$ fraction and micropore $(\leq 1.95 \mathrm{~nm})$ fraction were calculated as $80.25 \%$ and $31.50 \%$, respectively (Figure 21 ). The unique structural characteristics of the composite are expected to benefit the absorption of electrolytes and provide diffusion channels for electrolyte ions.

The XPS survey was performed to determine the surface chemical state of the $\mathrm{CNF} / \mathrm{MnO}_{x}$ composite aerogels, and the spectra of the $\mathrm{CNF} / \mathrm{MnO}_{x}-4$ are shown as representative examples. In the wide-scan spectrum (Figure 3a), the composition elements only contain C, O, and Mn, whereby the content of $\mathrm{C}$ is higher than the others, suggesting deep graphitization of CNF. This is also demonstrated by the fitting curve of the $C$ 1s profile that is related to $C-C$ bonds ( $\mathrm{sp}^{2}$ carbon) at a chemical shift of $284.5 \mathrm{eV}$ (Figure 3c). Mn can assume multiple oxidation states $\left(\mathrm{Mn}^{2+}, \mathrm{Mn}^{3+}\right.$, and $\left.\mathrm{Mn}^{4+}\right)$ and diverse phases during both oxidation and reduction processes. There are two peaks of $\mathrm{Mn} 2 \mathrm{p}_{1 / 2}$ and $\mathrm{Mn} 2 \mathrm{p}_{3 / 2}$, and the energy difference between these two peaks is $11.6 \mathrm{eV}$ (Figure 3b). According to the fitting curves of the $\mathrm{O} 1 \mathrm{~s}$ profile (Figure 3d), the three deconvoluted peaks can be assigned to the chemical bonds of Mn-O-Mn, Mn-O-H, and C-O at binding energies of 529.9, 531.4, and $532.7 \mathrm{eV}$, respectively. All these indicate that two kinds of manganese oxides are generated during the calcination process. The formation of a mixed-valent compound rather than single-phase $\mathrm{MnO}_{x}$ is attributed to oxygen deficiency during the calcination process. 

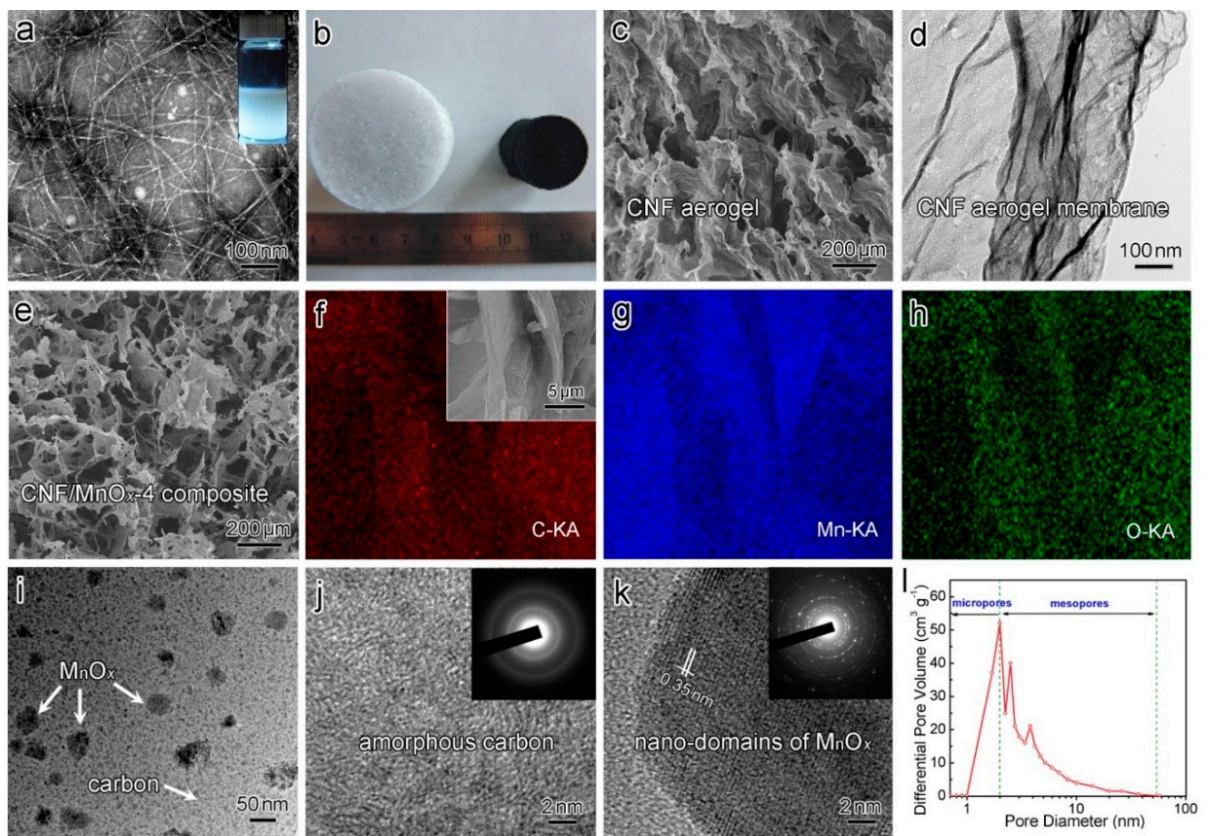

Figure 2. (a) Transmission electron microscope (TEM) image of nanocellulose fibers that extracted from wood biomass using a high-intensity ultrasonic nanofibrillation combined with chemical pretreatments. The inset in (a) shows the nanocellulose suspension. (b) Optical images of freeze-dried hybrid aerogel and the composite aerogel CNF/ $\mathrm{MnO}_{x}-4$. (c,d) Scanning electron microscope (SEM) and TEM images exhibiting the 3D structure of CNF aerogel, which is made of carbon nanofiber membranes. (e) SEM image showing the 3D porous structure of $\mathrm{CNF} / \mathrm{MnO}_{x}-4$. (f-h) SEM-Energy-dispersive X-ray (EDX) elemental mapping images show the electron probe microanalysis of $\mathrm{C}, \mathrm{Mn}$, and $\mathrm{O}$ elements, demonstrating the successful synthesis of $\mathrm{MnO}_{x}$ nanoparticles on the CNF membranes. (i) TEM image showing the $\mathrm{MnO}_{x}$ nanoparticles on CNF membranes. High-resolution TEM images showing ( $\mathbf{j}$ ) the amorphous carbon structure of CNF membranes, and (k) the crystalline nano-domains of $\mathrm{MnO}_{x}$ nanoparticles that attached on the supporting CNF membranes. The inset in ( $\mathbf{j}$ ) shows the selected area electron diffraction (SAED) cyclic pattern of amorphous carbon structure. The inset in (k) shows the SAED multi-sets of hexagonal spots of $\mathrm{MnO}_{x}$. (1) Pore size distribution of $\mathrm{CNF} / \mathrm{MnO}_{x}-4$.
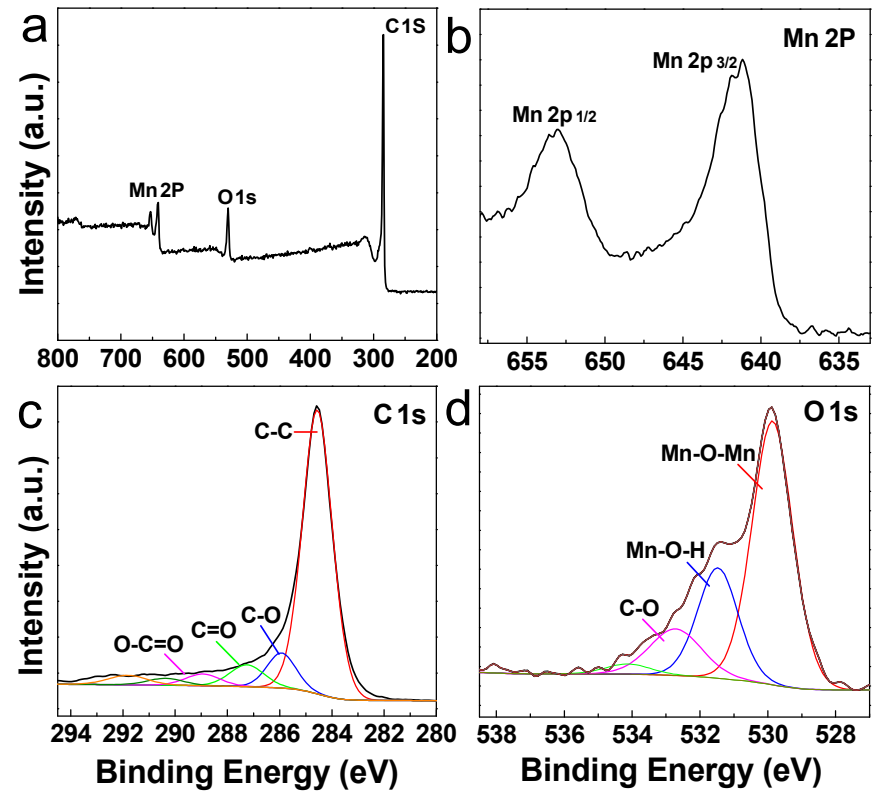

Figure 3. (a) X-ray photoelectron spectroscopy (XPS) survey spectrum of $\mathrm{CNF} / \mathrm{MnO}_{x}-4$. (b-d) XPS high-resolution spectra of Mn 2p, C 1s, and O 1s. 
The phase structure of the $\mathrm{CNF} / \mathrm{MnO}_{x}$ composite aerogels was further analyzed from a crystallographic perspective. Figure 4 shows the relevant XRD patterns. The wide amorphous peak in the range of $2 \theta=18-30^{\circ}$ is ascribed to CNF. A small diffraction peak is observed at $2 \theta=23.5^{\circ}$, which may be ascribed to the (002) lattice plane of highly graphitized carbon. The mixed crystals of $\mathrm{Mn}_{3} \mathrm{O}_{4}$ and $\mathrm{MnO}$ can be identified from the diffraction curves of the $\mathrm{CNF} / \mathrm{MnO}_{x}$ composites. The diffraction peaks (101), (112), (103), (211), (220), (224), and (400) at $2 \theta=18.02^{\circ}, 28.96^{\circ}, 32.42^{\circ}, 36.04^{\circ}, 44.36^{\circ}, 60.02^{\circ}$, and $64.66^{\circ}$, respectively, agree well with the $\mathrm{Mn}_{3} \mathrm{O}_{4}$ (faceted single crystals) powder standard (JCPDS 18-0803). The appearance of diffraction peaks at (111), (200), (220), (311), and (222) at $2 \theta=34.90^{\circ}, 40.54^{\circ}$, $58.72^{\circ}, 70.18^{\circ}$, and $73.80^{\circ}$, respectively, agrees well with the MnO powder standard (JCPDS 07-0230). A comparison of the peak intensities at $34.90^{\circ}, 40.54^{\circ}$, and $58.72^{\circ}$ that correspond to the lattice planes (111), (200), and (220), respectively, suggests that the appearance of a MnO phase was related to an increase of $\mathrm{Mn}(\mathrm{OAc})_{2}$ content. The limited supply of oxygen molecules cannot afford the oxidization of total $\mathrm{Mn}^{2+}$ to $\mathrm{Mn}^{3+}$. Thus, both the XRD patterns of $\mathrm{CNF} / \mathrm{MnO}_{x}-3$ and $\mathrm{CNF} / \mathrm{MnO}_{x}-4$ display the characteristic diffraction peaks of $\mathrm{MnO}$ and $\mathrm{Mn}_{3} \mathrm{O}_{4}$. Mixed-valent $\mathrm{MnO}_{x}$ usually contains both donor and acceptor sites in its microstructures as well as defects and mismatch induced by different phases, which can enable a high charge-storage capacity.

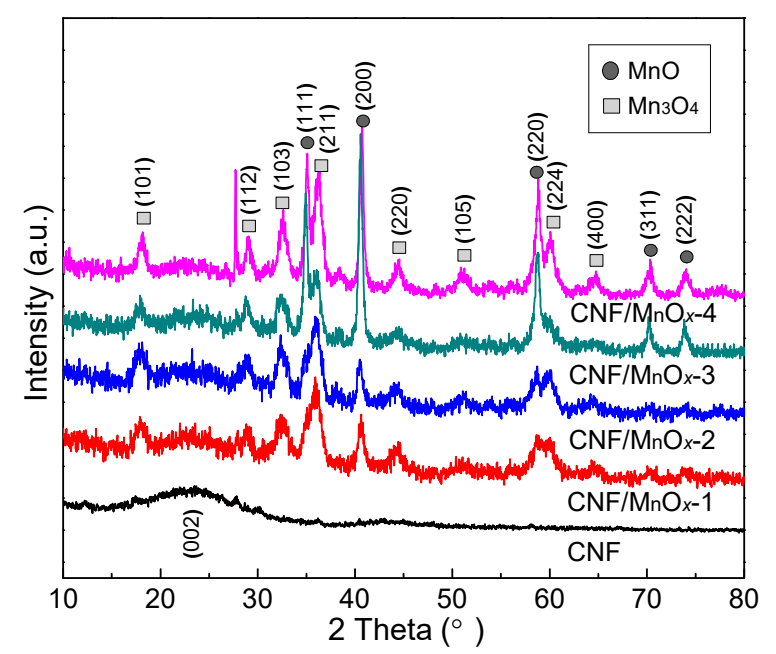

Figure 4. X-ray diffraction (XRD) patterns of CNF and CNF/MnO $x$ composite aerogels.

The electrochemical performance of the $\mathrm{CNF} / \mathrm{MnO}_{x}$ electrodes was evaluated from the $\mathrm{CV}$ measurements. All the $\mathrm{CNF} / \mathrm{MnO}_{x}$ composites exhibit symmetric quasi-rectangular $\mathrm{CV}$ shapes, indicating a high reversible charge-storage capacity (Figure 5a). This is attributed to the successive multiple surface redox reactions of $\mathrm{MnO}_{x}$, behaving with a charge-storage mechanism that is different from that of most metal oxides. No obvious oxidation and deoxidization peaks are observed, but orientation polarization is displayed. The hysteresis at a relative pressure between 0.4 and 0.5 confirms the existence of mesopores. At a high scan rate of $50 \mathrm{mV} \mathrm{s}^{-1}$, the $\mathrm{CNF} / \mathrm{MnO}_{x}$ electrodes also exhibit quasi-rectangular CV shapes, and the symmetry is improved (Figure 5b). As the scan rate is increased from 2 to $100 \mathrm{mV} \mathrm{s}^{-1}$, the response current improves and shows certain multiplying power characteristic, and the orientation polarization subsides (Figure 5c). The amount of $\mathrm{MnO}_{x}$ also has a significant influence on the specific capacitance of $\mathrm{CNF} / \mathrm{MnO}_{x}$ composites (Figure $5 \mathrm{~d}$ ). The specific capacitance of $\mathrm{CNF} / \mathrm{MnO}_{x}-1$ is $35.9 \mathrm{~F} \mathrm{~g}^{-1}$, which is similar to that of pure $\mathrm{CNF}\left(34.8 \mathrm{~F} \mathrm{~g}^{-1}\right)$. The specific capacitances of $\mathrm{CNF} / \mathrm{MnO}_{x}-2$ and $\mathrm{CNF} / \mathrm{MnO}_{x}-3$ are twice and three times that of pure $\mathrm{CNF}$. Notably, CNF/ $\mathrm{MnO}_{x}-4$ shows the highest specific capacitance $\left(138.4 \mathrm{~F} \mathrm{~g}^{-1}\right)$. The reduction of specific capacitance at high scan rates is assumed to be caused by the limiting redox reaction of $\mathrm{MnO}_{x}$ and hysteresis of the charge-transfer coefficient. When the mass fraction of $\mathrm{MnO}_{x}$ was further increased, the specific capacitance started to decrease (Figure S2). 

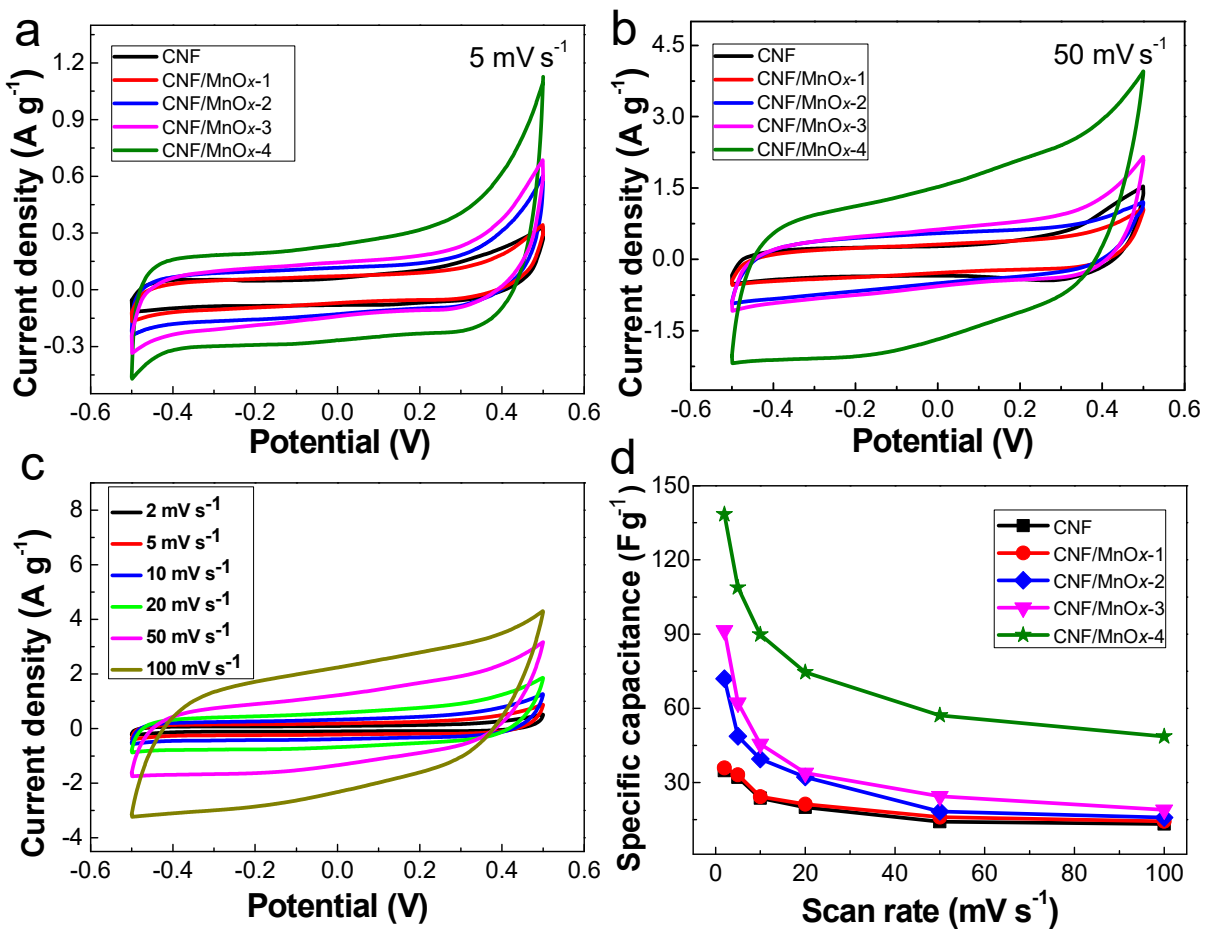

Figure 5. Cyclic voltammetry (CV) curves of the $\mathrm{CNF} / \mathrm{MnO}_{x}$ electrodes at a scan rate of (a) $5 \mathrm{mV} \mathrm{s}^{-1}$ and (b) $50 \mathrm{mV} \mathrm{s}^{-1}$. (c) Changes of CV curves of CNF/MnO $\mathrm{Mn}^{-4}$ at scan rates from 2 to $100 \mathrm{mV} \mathrm{s}^{-1}$. (d) Specific capacitance vs. scan rate.

The $\mathrm{CNF} / \mathrm{MnO}_{x}$ electrodes were evaluated by means of GCD measurements within -0.5 to $0.5 \mathrm{~V}$. The charge-discharge curves exhibit an almost triangular shape with a small internal resistance drop (Figure 6a). The deviation of the charge-discharge curves from the linear voltage-time relationship indicates a pseudocapacitive behavior. In aqueous electrolytes, the pseudo-capacitance of $\mathrm{MnO}_{x}$ comes from the intercalation and de-intercalation of protons and/or alkali ions, as well as redox reactions. The ion intercalation and de-intercalation and redox reactions take place on the surface of the $\mathrm{MnO}_{x}$ under high-speed charge-discharge. The presence of the internal resistance drop at the beginning of the discharge is usually associated with the equivalent series resistance phenomenon. At the same current density, the $\mathrm{CNF} / \mathrm{MnO}_{x}-4$ electrode shows superior performance to the others. The discharge curves of the $\mathrm{CNF} / \mathrm{MnO}_{x}-4$ electrode display a nearly linear response at different current densities from 0.25 to $2.0 \mathrm{~A} \mathrm{~g}^{-1}$ with a corresponding discharge time of $300 \mathrm{~s}$ and $30 \mathrm{~s}$, respectively (Figure 6b). Figure $6 \mathrm{c}$ shows a typical GCD curve of a $\mathrm{CNF} / \mathrm{MnO}_{x}-4$ electrode under continuous operation for the first several cycles, which indicates ideal electrochemical reversibility and almost symmetric charge-discharge properties. The specific capacitance can be calculated from the discharge curves using Equation (1) and shows a downward tendency with the rise of current density (Figure 6d). The Nyquist plot displays a typical diffusion-controlled Warburg capacitive behavior with a diagonal line in the low-frequency region and a small depressed semicircle in the high-frequency region. From the EIS results, the Nyquist plot shows an intercept at the real impedance $\left(Z^{\prime}\right)$ of $1.1 \Omega$ (Figure 6e). An elongated 'semicircle' can be attributed to the widely distributed pore sizes in the structure. The relatively small serial resistance suggests a compact electrode system that ensures fast charge transfer between electrolyte and electrodes. Figure $6 \mathrm{f}$ shows good electroconductivity of $\mathrm{CNF} / \mathrm{MnO}_{x}-4$ electrode in a series circuit. From above all, $\mathrm{CNF} / \mathrm{MnO}_{x}-4$ was selected as the optimal sample for constructing a symmetric supercapacitor. 

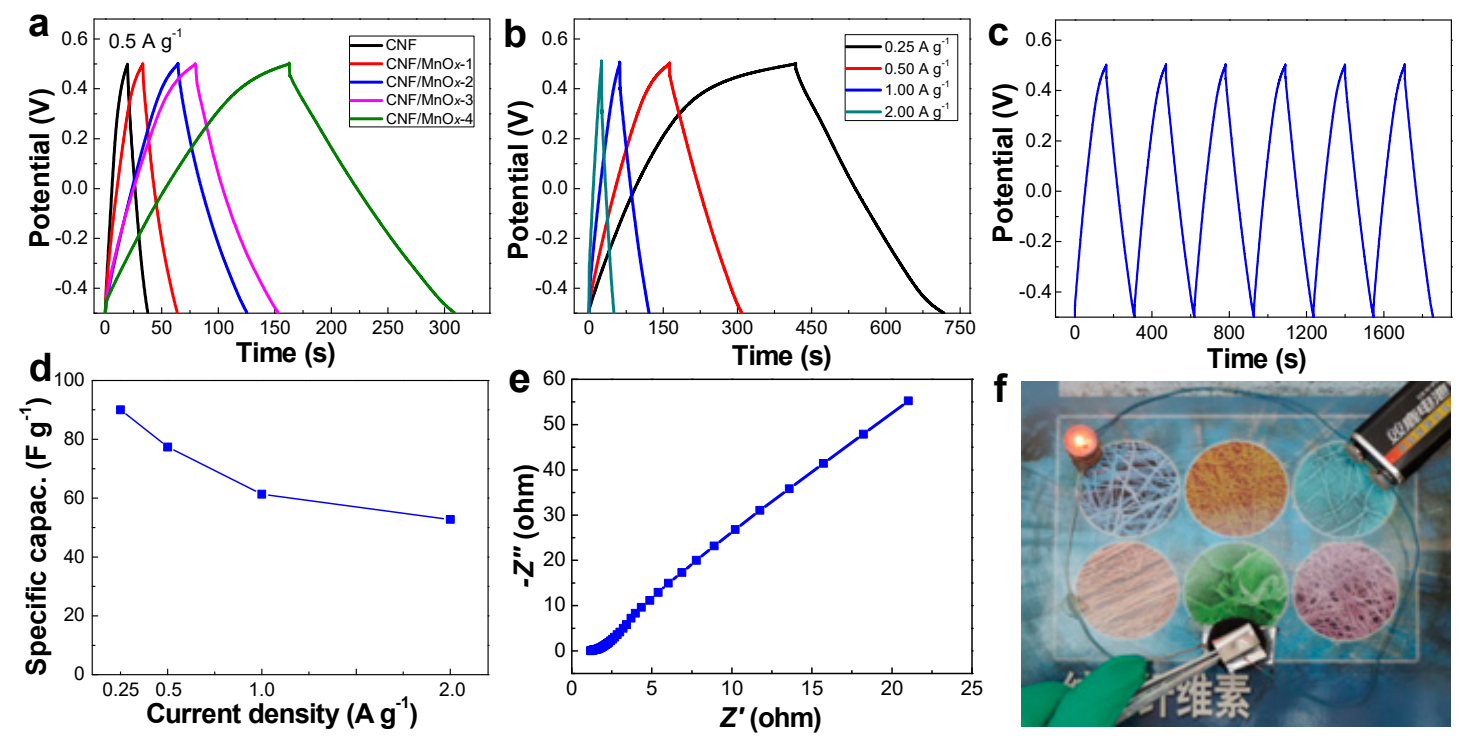

Figure 6. Galvanostatic charge-discharge (GCD) curves of the electrode made of $\mathrm{CNF} / \mathrm{MnO}_{x}$ electrodes. (a) Charge-discharge curves of $\mathrm{CNF} / \mathrm{MnO}_{x}$ electrodes in a three-electrode configuration measured at a constant current of $0.5 \mathrm{~A} \mathrm{~g}^{-1}$. (b) Charge-discharge curves of $\mathrm{CNF} / \mathrm{MnO}_{x}-4$ electrode at different current densities. (c) GCD curves of $\mathrm{CNF} / \mathrm{MnOx}-4$ electrode at a constant current of $0.5 \mathrm{~A} \mathrm{~g}^{-1}$. (d) Specific capacitance vs. current density of the $\mathrm{CNF} / \mathrm{MnO}_{x}-4$ electrode. (e) Nyquist plot for $\mathrm{CNF} / \mathrm{MnO}_{x}-4$ electrode. (f) Optical image shows the electroconductivity of $\mathrm{CNF} / \mathrm{MnO}_{x}-4$ electrode in a serial circuit.

Figure $7 \mathrm{a}$ is the schematic illustration of the $\mathrm{CNF} / \mathrm{MnO}_{x}-4$-based symmetric supercapacitor. Figure $7 \mathrm{~b}$ shows a series of rate-dependent $\mathrm{CV}$ curves of the $\mathrm{CNF} / \mathrm{MnO}_{x}$-4-based symmetric supercapacitor in the voltage range of 0-3.5 V. The CV measurements were conducted at a scan rate of $5,10,20,50$, and $100 \mathrm{mV} \mathrm{s}^{-1}$. Similar to the results measured in a three-electrode configuration, the assembled supercapacitor exhibited quasi-rectangular CV curves. Moreover, even at a high scan rate of $100 \mathrm{mV} \mathrm{s}^{-1}$, the $\mathrm{CV}$ curves remain symmetrical, suggesting good reversibility of the electrochemical processes. From the EIS results, the Nyquist plot shows an intercept at $Z^{\prime}$ of $4.6 \Omega$ (Figure 7c). Furthermore, the low-frequency region of the impedance curves shows a nearly straight sloping line, suggesting a good capacitive performance of the electrode. The calculated specific capacitances at different scan rates are present in Figure $7 \mathrm{~d}$. The $\mathrm{CNF} / \mathrm{MnO}_{x}$-4-based symmetric supercapacitor shows specific capacitances from $269.7 \mathrm{~F} \mathrm{~g}^{-1}$ to $108.6 \mathrm{~F} \mathrm{~g}^{-1}$ as the scan rate rises from 5 to $100 \mathrm{mV} \mathrm{s}^{-1}$. The specific capacitances represent an $80 \%$ retention of the initial capacitance after 1000 cycles of charging-discharging at $2 \mathrm{~A} \mathrm{~g}^{-1}$ (Figure 7e). 
a
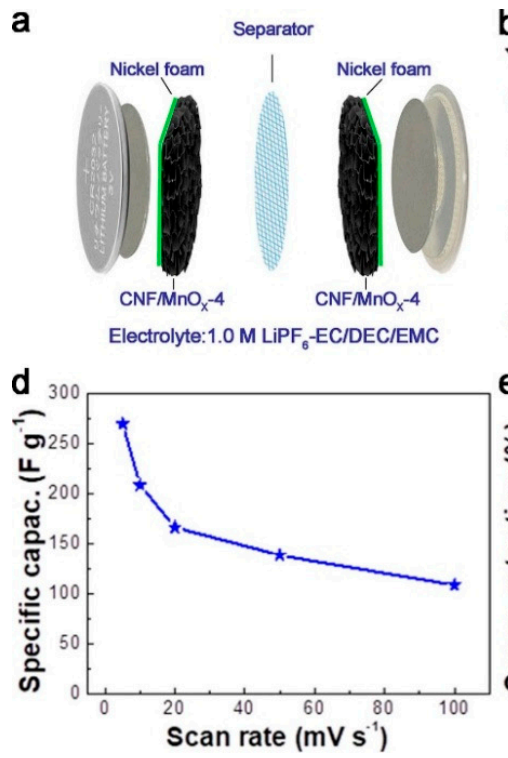
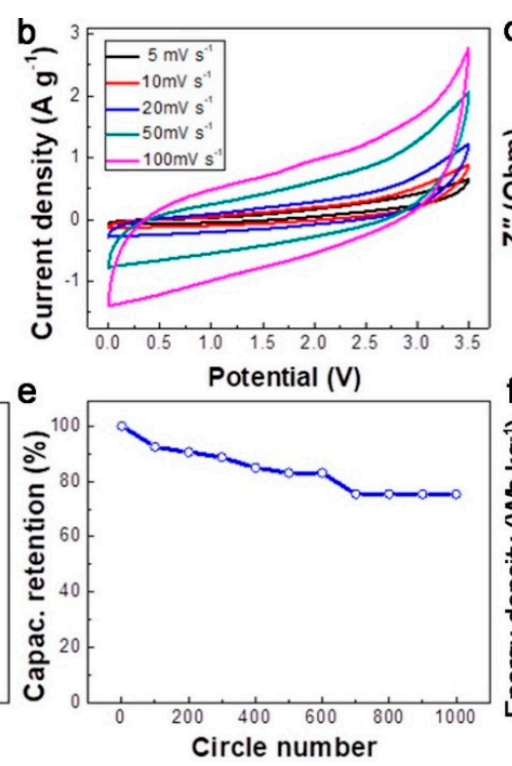
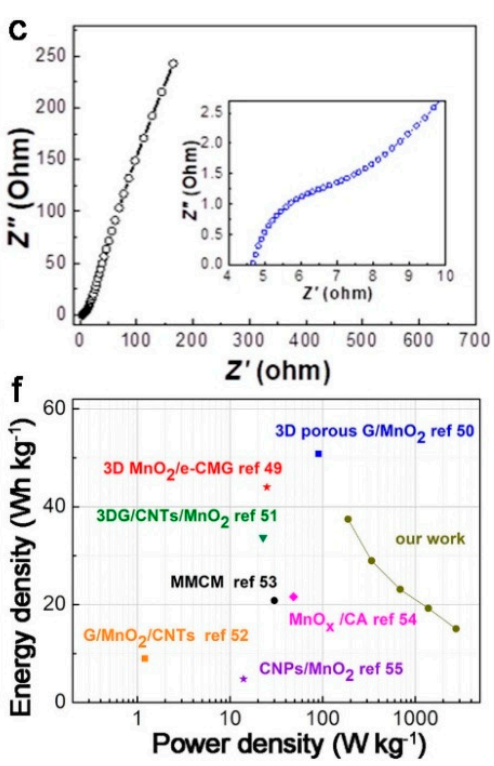

Figure 7. Electrochemical measurement of the $\mathrm{CNF} / \mathrm{MnO}_{x}-4$ based symmetric supercapacitor: (a) Schematic illustration of the $\mathrm{CNF} / \mathrm{MnO}_{x}$-4-based symmetric supercapacitor; (b) CV curves obtained at different scan rates; (c) Nyquist plots; (d) Specific capacitance vs. scan rate; (e) Cyclic stability at a charge-discharge current density of $2 \mathrm{~A} \mathrm{~g}^{-1}$ for 1000 cycles; (f) Ragone plot.

As noted from the CV and GCD studies, high energy density and power density are expected for such a supercapacitor assembly. Energy density and power density of the $\mathrm{CNF} / \mathrm{MnO}_{x}$-based symmetric supercapacitor are calculated from the GCD profiles and are illustrated in a Ragone plot (Figure 7f). A maximum energy density of $37.5 \mathrm{Wh} \mathrm{kg}^{-1}$ can be stored at a power density of $2.75 \mathrm{~kW} \mathrm{~kg}^{-1}$, under the same charge-discharge condition at a voltage of $3.5 \mathrm{~V}$. From the Ragone plot, the performance of our supercapacitor can compare with or superior to those of $\mathrm{CNT} / \mathrm{MnO}_{2}$-based supercapacitors and graphene $/ \mathrm{MnO}_{2}$-based supercapacitors [49-55] (e.g., 3D $\mathrm{MnO}_{2}$ /grapheme [49], graphene/CNT $/ \mathrm{MnO}_{2}$ [51], graphene/ $\mathrm{MnO}_{2} / \mathrm{CNT}$ supercapacitors [52]).

The satisfied performance of our supercapacitor is mainly contributed to the synergistic effects of material chemistry and structure on the electrochemistry performance of $\mathrm{CNF} / \mathrm{MnO}_{x}$-based electrodes, which are summarized and ascribed in the following aspects: (1) The mixture of nanocellulose suspension and $\mathrm{Mn}(\mathrm{OAc})_{2}$ solution is uniform and homogeneous, which prevents the aggregation of $\mathrm{MnO}_{x}$ colloids. (2) The CNF membranes are fabricated as the carbon aerogel carriers for $\mathrm{MnO}_{x}$ and nanoreservoirs for electrolytes. (3) A large number of research data have concluded that the electrical properties of carbon $/ \mathrm{MnO}_{x}$ composite depend on the mass fraction of $\mathrm{MnO}_{x}$. When the mass fraction of $\mathrm{MnO}_{x}$ is less than $70 \%$, the electrical properties increase with the increase of the mass of $\mathrm{MnO}_{x}$. In this experiment, the optimal $\mathrm{MnO}_{\mathrm{x}}$ loading is just half of the best, indicating a high utilization efficiency of $\mathrm{MnO}_{\mathrm{x}}$. (4) The web-like conductive percolating structure facilitates the diffusion path of electrolytes and reduces the charge-transfer impedance. Electrons can easily travel through the diffusion path and can be picked up by $\mathrm{MnO}_{4}{ }^{-}$ions at other locations. (5) The high electrical conductivity and low charge-transfer resistance improve the kinetics significantly and are favorable to overcome the kinetic limitations at high-current operation. (6) The integrated structure contains the essential components (electrodes, spacer, and electrolyte) of an electrochemical device, paving the way for designing a variety of energy-storage devices [43].

\section{Conclusions}

Freestanding $\mathrm{CNF} / \mathrm{MnO}_{x}$ composite aerogels were facilely synthesized by freeze-drying an aqueous dispersion of nanocellulose and $\mathrm{Mn}(\mathrm{OAc})_{2}$, followed by a calcination process. Despite the straightforward and inexpensive preparation, the shaped composites showed 3D porous structures 
with hierarchical pores, which benefit the transportation of both electrolyte ions and electrons. The composites exhibit quasi-rectangular CV curves, pseudocapacitive behavior, and small impedance. When used in a supercapacitor, the as-prepared $\mathrm{CNF} / \mathrm{MnO}_{x}$-based symmetric supercapacitor showed a specific capacitance of $269.7 \mathrm{~F} \mathrm{~g}^{-1}$ and possessed an energy density as high as $37.5 \mathrm{Wh} \mathrm{kg}^{-1}$, as well as a power density of $2.75 \mathrm{~kW} \mathrm{~kg}^{-1}$. Meanwhile, the supercapacitor displayed cyclic stability with capacitance retention of $80 \%$ after 1000 charge-discharge cycles at $2 \mathrm{~A} \mathrm{~g}^{-1}$. The approach is therefore highly promising in terms of both cost efficiency and scale-up for the development of renewable energy-storage devices toward sustainability.

Supplementary Materials: The following are available online at http:/ / www.mdpi.com/2073-4360/11/1/129/s1, Figure S1: TGA curves of $\mathrm{CNF} / \mathrm{MnO}_{x}$ composite aerogels, Figure S2: CV curves of the $\mathrm{CNF} / \mathrm{MnO}_{x}$ electrodes at scan rate of (a) $5 \mathrm{mV} \mathrm{s}^{-1}$ and (b) $50 \mathrm{mV} \mathrm{s}^{-1}$.

Author Contributions: H.Y. and Y.L. supervised the project. Q.L. and X.G. designed the research. X.G. carried out most of the experiments and analyzed the data. Q.Z. participated in the experiments. H.Y., Q.L. and X.G. discussed the results and prepared the manuscript.

Funding: This research was funded by the National Natural Science Foundation of China [31622016, 31800487], and the Natural Science Foundation of Heilongjiang Province of China [QC2018018].

Conflicts of Interest: The authors declare no competing interests.

\section{References}

1. Edberg, J.; Inganäs, O.; Engquist, I.; Berggren, M. Boosting the capacity of all-organic paper supercapacitors using wood derivatives. J. Mater. Chem. A 2018, 6, 145-152. [CrossRef]

2. Zhao, D.; Chen, C.; Zhang, Q.; Chen, W.; Liu, S.; Wang, Q.; Liu, Y.; Li, J.; Yu, H. High performance flexible solid-state supercapacitors based on a renewable and biodegradable mesoporous cellulose membrane. Adv. Energy Mater. 2017, 7, 1700739. [CrossRef]

3. Zhang, Y.; Wang, Y.; Cheng, T.; Lai, W.; Pang, H.; Huang, W. Flexible supercapacitors based on paper substrates: A new paradigm for low-cost energy storage. Chem. Soc. Rev. 2015, 44, 5181-5199. [CrossRef] [PubMed]

4. Pendashteh, A.; Senokos, E.; Palma, J.; Anderson, M.; Vilatela, J.J.; Marcilla, R. Manganese dioxide decoration of macroscopic carbon nanotube fibers: From high-performance liquid-based to all-solid-state supercapacitors. J. Power Sources 2017, 372, 64-73. [CrossRef]

5. Amir, F.Z.; Pham, V.H.; Schultheis, E.M.; Dickerson, J.H. Flexible, all-solid-state, high-cell potential supercapacitors based on holey reduced graphene oxide/manganese dioxide nanosheets. Electrochim. Acta 2018, 260, 944-951. [CrossRef]

6. He, W.; Wang, C.; Zhuge, F.; Deng, X.; Xu, X.; Zhai, T. Flexible and high energy density asymmetrical supercapacitors based on core/shell conducting polymer nanowires/manganese dioxide nanoflakes. Nano Energy 2017, 35, 242-250. [CrossRef]

7. Xu, Y.; Wang, S.; Ren, B.; Zhao, J.; Zhang, L.; Dong, X.; Liu, Z. Manganese oxide doping carbon aerogels prepared with $\mathrm{MnO}_{2}$ coordinated by $\mathrm{N}, \mathrm{N}$-dimethylmethanamide for supercapacitors. J. Colloid Interface Sci. 2019, 537, 486-495. [CrossRef]

8. Han, Z.J.; Seo, D.H.; Yick, S.; Chen, J.H.; Ostrikov, K.K. $\mathrm{MnO}_{x}$ / carbon nanotube/reduced graphene oxide nanohybrids as high-performance supercapacitor electrodes. NPG Asia Mater. 2014, 6, e140. [CrossRef]

9. Borenstein, A.; Hanna, O.; Attias, R.; Luski, S.; Brousse, T.; Aurbach, D. Carbon-based composite materials for supercapacitor electrodes: A review. J. Mater. Chem. A 2017, 25, 12653-12672. [CrossRef]

10. Xia, W.; Qu, C.; Liang, Z.; Zhao, B.; Dai, S.; Qiu, B.; Jiao, Y.; Zhang, Q.; Huang, X.; Guo, W.; et al. High-performance energy storage and conversion materials derived from a single metal-organic framework/graphene aerogel composite. Nano Lett. 2017, 17, 2788-2795. [CrossRef]

11. Jin, X.; Zhou, W.; Zhang, S.; Chen, G. Nanoscale microelectrochemical cells on carbon nanotubes. Small 2007, 3, 1513-1517. [CrossRef] [PubMed]

12. An, G.; Yu, P.; Xiao, M.; Liu, Z.; Miao, Z.; Ding, K.; Mao, L. Low-temperature synthesis of $\mathrm{Mn}_{3} \mathrm{O}_{4}$ nanoparticles loaded on multi-walled carbon nanotubes and their application in electrochemical capacitors. Nanotechnology 2008, 19, 275709-275716. [CrossRef] [PubMed] 
13. Zhang, H.; Cao, G.; Wang, Z.; Yang, Y.; Shi, Z.; Gu, Z. Growth of manganese oxide nanoflowers on vertically-aligned carbon nanotube arrays for high-rate electrochemical capacitive energy storage. Nano Lett. 2008, 8, 2664-2668. [CrossRef] [PubMed]

14. Wan, C.; Azumi, K.; Konno, H. Hydrated Mn(IV) oxide-exfoliated graphite composites for electrochemical capacitor. Electrochim. Acta 2007, 52, 3061-3066. [CrossRef]

15. Long, J.W.; Sassin, M.B.; Fischer, A.E.F.; Rolison, D.R. Multifunctional $\mathrm{MnO}_{2}$-carbon nanoarchitectures exhibit battery and capacitor characteristics in alkaline electrolytes. J. Phys. Chem. C 2009, 113, 17595-17598. [CrossRef]

16. Fischer, A.E.; Pettigrew, K.A.; Rolison, D.R.; Stroud, R.M.; Long, J.W. Incorporation of homogeneous nanoscale $\mathrm{MnO}_{2}$ within ultraporous carbon structures via self-limiting electroless deposition: Implications for electrochemical capacitors. Nano Lett. 2007, 7, 281-286. [CrossRef]

17. Cheng, Q.; Tang, J.; Ma, J.; Zhang, H.; Shinya, N.; Qin, L.C. Graphene and nanostructured $\mathrm{MnO}_{2}$ composite electrodes for supercapacitors. Carbon 2011, 49, 2917-2925. [CrossRef]

18. Cakici, M.; Kakarla, R.R.; Alonso-Marroquin, F. Advanced electrochemical energy storage supercapacitors based on the flexible carbon fiber fabric-coated with uniform coral-like $\mathrm{MnO}_{2}$ structured electrodes. Chem. Eng. J. 2017, 309, 151-158. [CrossRef]

19. Zhang, L.; Liu, Z.; Cui, G.; Chen, L. Biomass-derived materials for electrochemical energy storages. Prog. Polym. Sci. 2015, 43, 136-164. [CrossRef]

20. Chen, W.; Zhang, Q.; Uetani, K.; Li, Q.; Lu, P.; Cao, J.; Wang, Q.; Liu, Y.; Li, J.; Quan, Z.; et al. Sustainable carbon aerogels derived from nanofibrillated cellulose as high-performance absorption materials. Adv. Mater. Interfaces 2016, 3, 1600004. [CrossRef]

21. Berenguer, R.; García-Mateos, F.J.; Ruiz-Rosas, R.; Cazorla-Amorós, D.; Morallón, E.; Rodríguez-Mirasol, J.; Cordero, T. Biomass-derived binderless fibrous carbon electrodes for ultrafast energy storage. Green Chem. 2016, 18, 1506-1515. [CrossRef]

22. Karthikeyan, K.; Amaresh, S.; Lee, S.N.; Sun, X.; Aravindan, V.; Lee, Y.G.; Lee, Y.S. Construction of high-energy-density supercapacitors from pine-cone-derived high-surface-area carbons. ChemSusChem 2014, 7, 1435-1442. [CrossRef] [PubMed]

23. Tian, W.; Gao, Q.; Tan, Y.; Li, Z. Unusual interconnected graphitized carbon nanosheets as the electrode of high-rate ionic liquid-based supercapacitor. Carbon 2017, 119, 287-295. [CrossRef]

24. Zhang, W.; Lin, N.; Liu, D.; Xu, J.; Sha, J.; Yin, J.; Tan, X.; Lu, H.; Lin, H. Direct carbonization of rice husk to prepare porous carbon for supercapacitor applications. Energy 2017, 128, 618-625. [CrossRef]

25. Pang, J.; Zhang, W.; Zhang, H.; Zhang, J.; Zhang, H.; Gao, G.; Han, M.; Yang, Y. Sustainable nitrogen-containing hierarchical porous carbon spheres derived from sodium lignosulfonate for high-performance supercapacitors. Carbon 2018, 132, 280-293. [CrossRef]

26. Bommier, C.; Xu, R.; Wang, W.; Wang, X.; Wen, D.; Lu, J.; Ji, X. Self-activation of cellulose: A new preparation methodology for activated carbon electrodes in electrochemical capacitors. Nano Energy 2015, 13, 709-717. [CrossRef]

27. Hu, W.; Yoshida, N.; Hirota, Y.; Tanaka, S.; Nishiyama, N. Solvothermal co-gelation synthesis of N-doped three-dimensional open macro/mesoporous carbon as efficient electrocatalyst for oxygen reduction reaction. Electrochem. Commun. 2017, 75, 9-12. [CrossRef]

28. Dutta, S.; Bhaumik, A.; Wu, K.C.W. Hierarchically porous carbon derived from polymers and biomass: Effect of interconnected pores on energy applications. Energy Environ. Sci. 2014, 7, 3574-3592. [CrossRef]

29. Liu, M.; Shi, M.; Lu, W.; Zhu, D.; Li, L.; Gan, L. Hierarchically porous carbon with manganese oxides as highly efficient electrode for asymmetric supercapacitors. Chem. Eng. J. 2017, 7, 518-526. [CrossRef]

30. Hou, J.; Cao, C.; Idrees, F.; Ma, X. Hierarchical porous nitrogen-doped carbon nanosheets derived from silk for ultrahigh-capacity battery anodes and supercapacitors. ACS Nano 2015, 9, 2556-2564. [CrossRef]

31. Deng, J.; Xiong, T.; Xu, F.; Li, M.; Han, C.; Gong, Y.; Wang, H.; Wang, Y. Inspired by bread leavening: One-pot synthesis of hierarchically porous carbon for supercapacitors. Green Chem. 2015, 17, 4053-4060. [CrossRef]

32. Pääkkö, M.; Vapaavuori, J.; Silvennoinen, R.; Kosonen, H.; Ankerfors, M.; Lindström, T.; Berglund, L.A.; Ikkala, O. Long and entangled native cellulose I nanofibers allow flexible aerogels and hierarchically porous templates for functionalities. Soft Matter 2008, 4, 2492-2499. [CrossRef]

33. Chen, W.; Li, Q.; Wang, Y.; Yi, X.; Zeng, J.; Yu, H.; Liu, Y.; Li, J. Comparative study of aerogels obtained from differently prepared nanocellulose fibers. ChemSusChem 2014, 7, 154-161. [CrossRef] [PubMed] 
34. Wang, Z.; Carlsson, D.O.; Tammela, P.; Hua, K.; Zhang, P.; Nyholm, L.; Strømme, M. Surface modified nanocellulose fibers yield conducting polymer-based flexible supercapacitors with enhanced capacitances. ACS Nano 2015, 9, 7563-7571. [CrossRef] [PubMed]

35. Ding, Q.; Xu, X.; Yue, Y.; Mei, C.; Huang, C.; Jiang, S.; Wu, Q.; Han, J. Nanocellulose-mediated electroconductive self-healing hydrogels with high strength, plasticity, viscoelasticity, stretchability, and biocompatibility toward multifunctional applications. ACS Appl. Mater. Interfaces 2018, 10, 27987-28002. [CrossRef]

36. Yu, H.; Chen, P.; Chen, W.; Liu, Y. Effect of cellulose nanofibers on induced polymerization of aniline and formation of nanostructured conducting composite. Cellulose 2014, 6, 1757-1767. [CrossRef]

37. Zhu, H.; Fang, Z.; Preston, C.; Li, Y.; Hu, L. Transparent paper: Fabrications, properties, and device applications. Energy Environ. Sci. 2014, 7, 269-287. [CrossRef]

38. Choi, K.-H.; Cho, S.-J.; Chun, S.-J.; Yoo, J.T.; Lee, C.K.; Kim, W.; Wu, Q.; Park, S.-B.; Choi, D.-H.; Lee, S.-Y.; et al. Heterolayered, one-dimensional nanobuilding block mat batteries. Nano Lett. 2014, 14, 5677-5686. [CrossRef]

39. Hu, L.; Choi, J.W.; Yang, Y.; Jeong, S.; La Mantia, F.; Cui, L.-F.; Cui, Y. Highly conductive paper for energy-storage devices. Proc. Natl. Acad. Sci. USA 2009, 51, 21490-21494. [CrossRef]

40. Hamedi, M.; Karabulut, E.; Marais, A.; Herland, A.; Nyström, G.; Wågberg, L. Nanocellulose aerogels functionalized by rapid layer-by-layer assembly for high charge storage and beyond. Angew. Chem. Int. Ed. 2013, 52, 12038-12042. [CrossRef]

41. Li, Y.; Zhu, H.; Shen, F.; Wan, J.; Han, X.; Dai, J.; Dai, H.; Hu, L. Highly conductive microfiber of graphene oxide templated carbonization of nanofibrillated cellulose. Adv. Funct. Mater. 2014, 24, 7366-7372. [CrossRef]

42. Jiao, F.; Edberg, J.; Zhao, D.; Puzinas, S.; Khan, Z.U.; Mäkie, P.; Naderi, A.; Lindström, T.; Odén, M.; Engquist, I.; et al. Nanofibrillated cellulose-based electrolyte and electrode for paper-based supercapacitors. Adv. Sustain. Syst. 2018, 2, 1700121. [CrossRef]

43. Chen, C.; Bu, X.; Feng, Q.; Li, D. Cellulose nanofiber/carbon nanotube conductive nano-network as a reinforcement template for polydimethylsiloxane nanocomposite. Polymers 2018, 10, 1000. [CrossRef]

44. Yang, C.; Chen, C.; Pan, Y.; Li, S.; Wang, F.; Li, J.; Li, N.; Li, X.; Zhang, Y.; Li, D. Flexible highly specific capacitance aerogel electrodes based on cellulose nanofibers, carbon nanotubes and polyaniline. Electrochim. Acta 2015, 182, 264-271. [CrossRef]

45. Yang, X.; Shi, K.; Zhitomirsky, I.; Cranston, E.D. Cellulose nanocrystal aerogels as universal 3D lightweight substrates for supercapacitor materials. Adv. Mater. 2015, 27, 6104-6109. [CrossRef] [PubMed]

46. Chen, W.; Yu, H.; Liu, Y.; Chen, P.; Zhang, M.; Hai, Y. Individualization of cellulose nanofibers from wood using high-intensity ultrasonication combined with chemical pretreatments. Carbohydr. Polym. 2011, 83, 1804-1811. [CrossRef]

47. Chen, W.; Li, Q.; Cao, J.; Liu, Y.; Li, J.; Zhang, J.; Luo, S.; Yu, H. Revealing the structures of cellulose nanofiber bundles obtained by mechanical nanofibrillation methods via TEM observation. Carbohydr. Polym. 2015, 117, 950-956. [CrossRef]

48. Chen, P.; Yu, H.; Liu, Y.; Chen, W.; Wang, X.; Ouyang, M. Concentration effects on the isolation and dynamic rheological behavior of cellulose nanofibers via ultrasonic processing. Cellulose 2013, 20, 149-157. [CrossRef]

49. Choi, B.G.; Yang, M.H.; Hong, W.H.; Choi, J.W.; Huh, Y.S. 3D macroporous graphene frameworks for supercapacitors with high energy and power densities. ACS Nano 2012, 6, 4020-4028. [CrossRef]

50. Shao, Y.; Wang, H.; Zhang, Q.; Li, Y. High-performance flexible asymmetric supercapacitors based on 3D porous graphene $/ \mathrm{MnO}_{2}$ nanorod and graphene/Ag hybrid thin-film electrodes. J. Mater. Chem. C 2013, 1, 1245-1251. [CrossRef]

51. Chen, W.; He, Y.; Li, X.; Zhou, J.; Zhang, Z.; Zhao, C.; Gong, C.; Li, S.; Pan, X.; Xie, E. Facilitated charge transport in ternary interconnected electrodes for flexible supercapacitors with excellent power characteristics. Nanoscale 2013, 5, 11733-11741. [CrossRef] [PubMed]

52. Cheng, Y.; Lu, S.; Zhang, H.; Varanasi, C.V.; Liu, J. Synergistic effects from graphene and carbon nanotubes enable flexible and robust electrodes for high-performance supercapacitors. Nano Lett. 2012, 12, 4206-4211. [CrossRef] [PubMed]

53. Jiang, H.; Yang, L.; Li, C.; Yan, C.; Lee, P.S.; Ma, J. High-rate electrochemical capacitors from highly graphitic carbon-tipped manganese oxide/mesoporous carbon/manganese oxide hybrid nanowires. Energy Environ. Sci. 2011, 4, 1813-1819. [CrossRef] 
54. Lin, Y.H.; Wei, T.Y.; Chien, H.C.; Lu, S.Y. Manganese oxide/carbon aerogel composite: An outstanding supercapacitor electrode material. Adv. Energy Mater. 2011, 1, 901-907. [CrossRef]

55. Yuan, L.; Lu, X.H.; Xiao, X.; Zhai, T.; Dai, J.; Zhang, F.; Hu, B.; Wang, X.; Gong, L.; Chen, J.; et al. Flexible solid-state supercapacitors based on carbon nanoparticles $/ \mathrm{MnO}_{2}$ nanorods hybrid structure. ACS Nano 2012, 6, 656-661. [CrossRef] [PubMed] 